\title{
Revisiting Question of Evaporation Mathematical Modeling Process
}

\section{Alexander Beljaev ${ }^{1}$,Alexander Salugin ${ }^{1}$, and Elena Vorontsova ${ }^{2,3}$}

${ }^{1}$ Federal Scientific Centre of agroecology, complex meliorations and protective afforestation of Russian Academy of Sciences, Volgograd, Russia

${ }^{2}$ All-Russian Research Institute of Irrigated Agriculture, Volgograd, Russia

${ }^{3}$ Volgograd State Agrarian University, Volgograd, Russia

\section{Abstract}

The methods of mathematical description of evaporation processes from light soils of the arid zone of Russia are discussed. The focus is on the evaporation of moisture from the aeration zone. The analysis of theoretical work in this area and the results of their practical implementation are presented. Mathematical models of evaporation are divided into two types: physical and mathematical, taking into account the interaction of moisture with the soil frame and phenomenological, based on balance relations with the use of ordinary differential equations. The analysis of the actual material on

Corresponding Author:

Elena Vorontsova

fsd_58@mail.ru

Received: 25 October 2019

Accepted: 15 November 2019

Published: 25 November 2019

Publishing services provided by Knowledge E

(c) Alexander Beljaev et al. This article is distributed under the terms of the Creative Commons Attribution License, which permits unrestricted use and redistribution provided that the original author and source are credited.

Selection and Peer-review under the responsibility of the AgroSMART 2019 Conference Committee.

\section{G OPEN ACCESS} evaporation from light soils of the Privolzhskiy sands was carried out in the light of the theory of evaporation from the capillaries surface in the pore space, taking into account the diffusion and film movements of moisture. A semi-empirical model of moisture movement in the upper soil layers in the form of analytical formulas relating the evaporation rate to the physical state of the soil water was used to estimate the water loss during evaporation. Good agreement was obtained between the theoretical provisions on the capillary movement of moisture and the data on evaporation from the sandy soils of the steppe zone of Russia. Approximation of data on the precipitation falling dynamics during the year by semi-empirical dependencies in the form of analytical formulas determines their practical use in the work of agricultural producers.

Keywords: evaporation, porosity, aeration zone, pressure gradient, humidity, capillary radius, surface tension, mathematical modeling, soil-plant systems, computational experiment

\section{Introduction}

The process of evaporation from the porous soil space is one of the main ones in the water balance of arid territories. The evaporation dynamics determines the soil moistening conditions, the provision of plants with water supply in order to make yield forecasts. The conservation of moisture in areas with its deficit is one of the main tasks in water management. The study of evaporation as a process in space and time was carried out by researchers for a considerable time. Mainly, evaporation from the water surface and soil horizons was investigated depending on geographic location and 
climate. However, the physical processes accompanying evaporation from the depth of the soil are poorly investigated. Basically, evaporation is studied as a phenomenon of moisture transfer at the level of water-balance relations as physical evaporation [1--8]. The due attention was paid to the influence of climatic factors (temperature, atmospheric air humidity, duration and frequency, etc.) at the level of a phenomenological description of the specific climatic zone (region) water balance dynamics.

The theoretical papers $[5,7]$ are devoted to the mechanism of capillary structures evaporation in the stationary evaporation approximation. The evaporation rate in these researches was determined by the vapor diffusion flux and the liquid flux transferred due to the thickness gradient in the capillary (film transfer). The evaporation capillary model [5] made it possible to identify the relationship between evaporation, film thickness, relative humidity, and the model capillary radius. It turned out that in capillaries with a radius of $r<10^{-5} \mathrm{~cm}$, the evaporation rate increases 10 or more times as compared with large capillaries $\left(r>10^{-2} \mathrm{~cm}\right)$. In the process of isothermal evaporation, this position was experimentally proved in the works of N.V. Churaev [7].

The author found that the rate of evaporation may depend on the prehistory (hysteresis).

\section{Methods and Equipment}

\subsection{Methods}

\subsubsection{Mathematical models of evaporation}

The study of evaporation from capillary-porous soil in the work [5] was based on the theory of capillary evaporation. The authors note that at constant relative humidity of atmospheric air $\left(\varphi_{0}<1\right)$, evaporation leads to the formation of capillaries with concave meniscuses. All the capillaries in their models were conditionally divided into two "varieties" -- large $r_{1}$ and small $r_{2}$. For large amounts of evaporated moisture will be

$$
q=\frac{D p_{s} M F_{1}\left(\phi_{1}-\phi_{0}\right)}{R T\left(x+x_{0}\right)}
$$

where $F_{1}$ is the total evaporation area, $D$ is the diffusion coefficient of vapor in air, $p_{s}$ is the partial pressure of saturated steam at temperature $T, M$ is the mass of a gram molecule of water, $R$ is the universal annual constant, $\varphi_{1}$ is the relative humidity above the meniscus with radius $r_{1}, \varphi_{0}$ is a relative humidity of atmospheric air, $x_{0}$ is the upper boundary of the meniscus (the level of the surface), $x$ is the lowering of the meniscus. Under the meniscus, relative humidity differs from atmospheric because of the influence 
of surface tension. Capillaries with a large radius were introduced in order to evaluate the effect of film moisture. In the process of evaporation, moisture will be removed from both types of capillaries with different capillary pressure. This difference determines the position $(x)$ levels of those and other capillaries.

In this work, three stages of the evaporation process were identified. In the first stage, evaporation drops rapidly. In the practice of calculating the evaporation from light soils $\left(r_{2}>10^{-5} \mathrm{~cm}\right)$, it is possible to use the formula (2):

$$
I \approx I_{0}\left(1-\frac{n x}{x+x_{0}}\right)
$$

where $I$ is the evaporation rate from the meniscus surface, located at $x$ level from the day surface; $n$ is thin capillaries surface fraction of the total evaporation area; $I_{0}$ is evaporation from the surface $x_{0}$. The evaporation intensity decreases with time from $I=I_{0}$ $(x=0)$ to $I / I_{0}=1--n=$ const. Thus, steady-state evaporation depends on the ratio between the number of large and small pores in the soil structure. Introducing the concept of average humidity, reflecting the filling of the pore space

$$
w=1-\frac{n x}{L},
$$

where $L$ is the depth of the aeration zone, it is possible to proceed to the dependence of evaporation on humidity:

$$
I \approx I_{0}\left(1-\frac{n(1-w L)}{1-w L+n x_{0}}\right)
$$

As the result, a dynamic evaporation equation was obtained, which showed that there is a time segment with a constant evaporation rate (Figure 1). At the same time, the distance between the positions of the meniscus changes, determining the intensity of moisture evaporation from the capillaries.

The relative evaporation rate $I / I_{0}$ was calculated for two cases. Case (a) in the figure corresponds to the conditions when the contribution of film transfer is insignificant. This can take place at low relative humidity of air $\varphi_{0}<0.9$ and large pores with sizes $r_{2}>10^{-3}$ $\mathrm{cm}$. In case (b), film moisture predominates. As can be seen from the graphs, the film movement of moisture contributes to evaporation over a longer period. The evaporation process at the very beginning exposes a new row of capillaries emerging to the surface. At the same time, the evaporation rate will decrease until there is a balanced exchange of moisture between small and large capillaries by the film mechanism. 


\section{Results}

Nerpin S.V. model in the considered formulation is simplified, since it does not take into account the size effects associated with soil shrinkage upon drying. It "works" to describe the evaporation of light soils with a low content of dust fractions. The theoretical graphs presented in Figure 1 -- curve 2, coincide qualitatively with Gardner experimental observations [10].

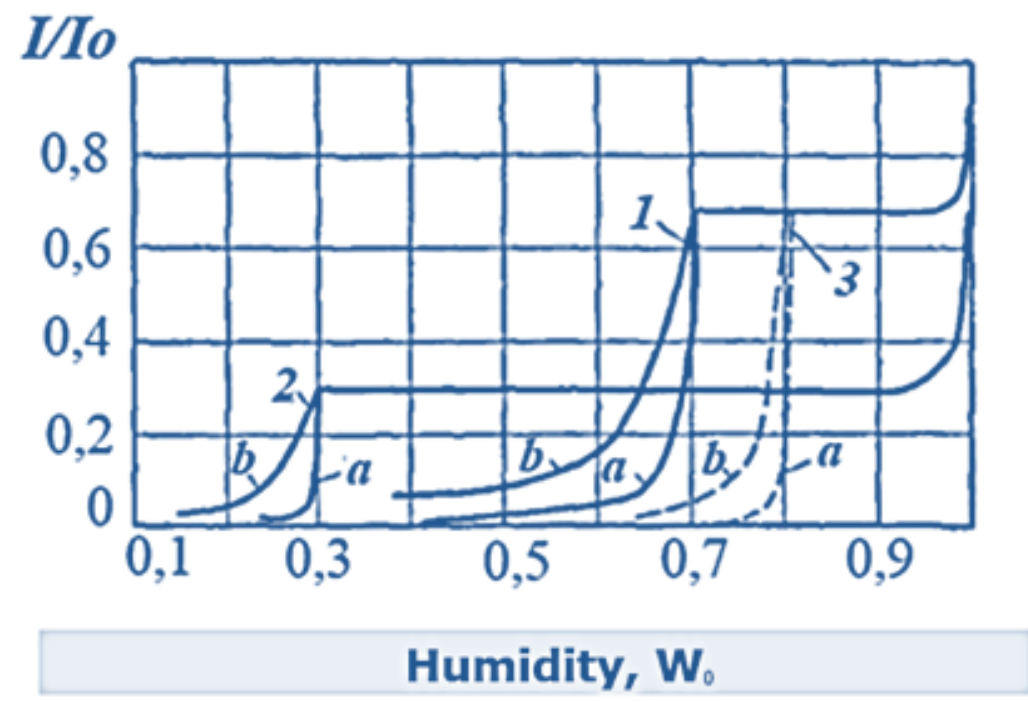

Figure 1: Relative evaporation intensity dependence on humidity, obtained from the capillary model [10]: 1 $n=0.3 ; L=100 ; 2-n=0.7 ; L=100 ; 3-n=0.3 ; L=200 ; n$ is the relative content of capillaries in the clay fraction; $L$ is the depth of aeration zone $(\mathrm{cm})$.

A model built on such approximations made it possible to establish very important points for the dynamics of evaporation from porous media. The dependence of the partial pressure of steam on the meniscus coordinates in large pores was obtained. This is the main task of soil hydrologists -- how much moisture rises along the capillary fringe, taking into account the removal of water from the pore space during evaporation from the surface daily layer.

The authors [1-3] noted that the intensity of evaporation depends on the hydrophysical properties of soils, their moisture content and the soil potential (pressure). The nonlinear behavior of this dependence reflects the inverse relationship between evaporation and soil moisture: as the water in the soil decreases, evaporation decreases because of evaporation. In this case, the dependence of evaporation intensity I on moisture $w$ increase with an increase in soil dispersity: with an increase in the content of the dust fraction with a particle size of 0.05--0.001 mm in sandy soils, evaporation increases. Thus, in light sandy soils, the evaporation rate decreases in the series: "sand -- sandy loam -- loam". Interpreting the results obtained, the authors associate 
the evaporation process with a change in the soil moisture pressure from maximum hygroscopic $(\mathrm{MH})$ to total moisture capacity (TMC). Laboratory methods were used to determine the characteristic humidity and to identify the evaporation general patterns: regardless of granulometric content of the studied soil and ground, every hydrophysical humidity corresponds to a certain range of evaporation intensity. For all soils, the highest evaporation was observed at humidity equal to the total moisture capacity. With a capillary moisture capacity, the evaporation rate is $0.04 \mathrm{~g} / \mathrm{h} \cdot \mathrm{cm}^{2}$, and at the maximum hygroscopic humidity, evaporation almost stops.

During evaporation, due to the moisture transfer from capillary to capillary-butt, existing in the form of cuffs at the joints of sand particles, the water energy binding with the solid surface of soil particles increases. Further, evaporation captures more water related categories and its evaporation decreases. Thus, the rate of water evaporation, all other conditions being the same, is determined by the water specific category presence in the soil, which is closely related to the moisture potential.

The soil moisture potential is characterized by the "water retention curve" -- the main hydro-physical characteristic -- dependence of the moisture pressure on the soil moisture $w$ [11--14]. The process of retention is associated with the soil ability to retain moisture due to the different forces of the soil frame --- capillary, film, and sorption. The greater the humidity at a given pressure -- the higher the water-holding capacity of the soil. With an increase in the dispersity, the water retention curves are shifted to the right --- toward the side of high humidity values [11--12, 16, 28]. It is obvious that the evaporation process -- the detachment of water molecules from the surface layer -- is energetically associated with the state of this surface, which, in turn, is determined by the subsurface (matrix) pressure $(P)$. Based on these assumptions, we turned to our data obtained in the course of the "restoration" of the main hydrophysical characteristic [14] with a view to applying to the estimates of physical evaporation on soils with different contents of the silt fraction.

The comparison of the evaporation intensity I and humidity $w$ with the dependence of pressure $P$ on humidity -- $P(w)$ made it possible to establish a functional relationship between soil pressure and evaporation [3]. It turned out that for sandy soils with increasing pressure, the evaporation rate decreases for all samples. At the same time, a qualitative correspondence with the capillary theory of Nerpin S.V. -- the evaporation rate begins to decrease immediately at the beginning of the process for coarse fractions (at $P=0$ ), while in finely dispersed sands, the value of $I$ has a gentle time period, decreasing with increasing moisture potential, starting from $P=0,492 \cdot 10^{-2}$ Bar. From the experimental data of the work [3], it follows that for each moisture pressure and 
bulk humidity there is a rather narrow interval of evaporation intensity $I$. Curves I (P) demonstrate that the transition to the second decreasing evaporation stage occurs at a humidity equal to $\mathrm{HB}$, and the evaporation intensity becomes close to zero at maximum hygroscopic one. Moreover, for $P>0.001$ Bar, the $I(P)$ dependence is approximated by a power dependence $I=I_{0} \cdot P^{n}$, where $I_{0}$ is the evaporation rate $\left(\mathrm{kg} /\left(\mathrm{cm}^{2}\right) ; I_{0}\right.$ is the intensity of water evaporation from soils at a moisture pressure of $1.0 \mathrm{MPa}(\mathrm{kg} / \mathrm{cm} 2) ; P$ is the moisture pressure; $n$ is a dimensionless coefficient. The difficulties in interpreting the $I(P)$ curves are that soil water is usually under the influence of several forces of different nature, and the transition from one form to another "blurred": does not occur at any one strictly defined amount of humidity, but in some spacing.

Analyzing the patterns of evaporation in soils, it can be concluded that each specific value of the moisture pressure and each hydrophysical humidity determine the corresponding intensity of evaporation. Based on this, the authors conclude that the averaged dependence $I(P)$ can be used for any soil using the formula $I=I_{0} \cdot P^{n}$ with coefficients $I_{0}=$ $1.9310^{-4}$ Bar and $n=--0.21$. It establishes the link between evaporation and pressure of moisture in the soil, and the physical meaning is that each category of soil moisture in the aeration zone has its own evaporation intensity. Using this equation, it is possible to predict the moisture pressure from which evaporation occurs, and, conversely, to determine the possible intervals of evaporation intensity for each category of water in the soil.

\section{Discussion}

The given theoretical and experimental results can be used for practical calculations and forecasts of evaporation of moisture from soils with a similar structure. Most researchers consider the issues of soil hydrology and water balance, defining evaporation as the sum of transpiration (desuction) and the actual evaporation -- physical evaporation [2--6, $16,18]$. This is due to the complexity of the separation of these processes, as well as the fact that they are implemented almost always at the same time and when calculating water consumption norms are taken into account together.

The simplest definition of evaporation is demonstrated by the water balance method. According to the water reserves at the beginning and end of observations and by the amount of precipitation (in the absence of runoff), evaporation can be calculated with sufficient accuracy. This method was used by the author [9] to determine evaporation in hydrological areas with an impermicidal horizon. In the summer period, the observations in the field and laboratory conditions established an empirical dependence of physical 
evaporation on the moisture of the soil top layer. When the humidity is equal to the lowest and above it, evaporation is close to evaporation from the water surface. In summer, such humidification is rarely within a few hours immediately after precipitation. When a dried layer appears, the evaporation rate decreases sharply.

Figure 2 demonstrates the theoretical curve obtained by the authors [5] for approximation of evaporation, as the function of the evaporation surface depth. It is clear from the figure that there is a good agreement between the theoretical dependence and the observations. The curve was fitted using the non-linear regression function of the Matlab least-squares package using the Gauss-Newton method. The high degree of theoretical and experimental data coincidence attracts attention, without looking at a limited number of measurements.

In work [4], evaporation was measured on open sands and under the forest stretch (Figure 3). After more than $3 \mathrm{~mm}$ of precipitation falls within one day, 2--3 mm evaporate, and $1-1.5 \mathrm{~mm}$ is under the forest canopy.

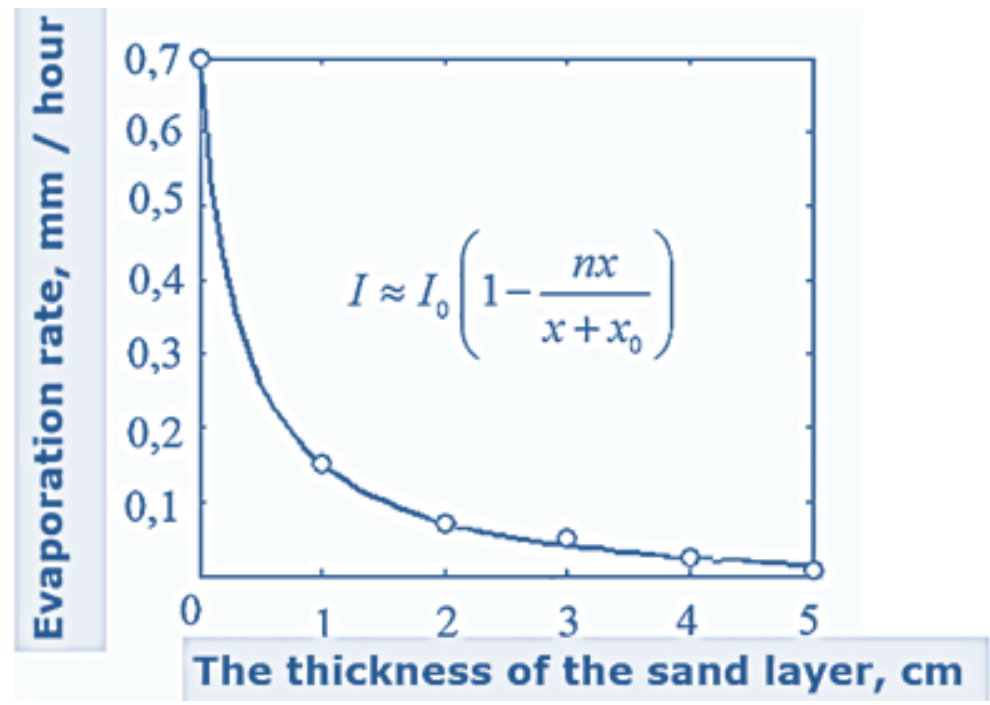

Figure 2: Evaporation rate dependence on the dry sand layer thickness. Approximation of function (2) with parameters $n=0.7 ; x_{0}=0.34 \mathrm{~cm}$.

The author noted that the values of daily evaporation on the Nizhnedneprovsk and Privolzhskiy sands are close to each other and depend only on the thickness of the surface dry horizon. A characteristic feature of physical evaporation in the summer period is its high intensity in the first days after precipitation and a sharp decrease in the following days. From the point of view of the capillary theory of evaporation by Nerpin, discussed above, this corresponds to the beginning (first stage) of evaporation. On the first day, the surface layer $x_{0}$ evaporates with an initial intensity $I_{0}$. Then, after the upper layer has dried up before the appearance of capillaries, the evaporation rate drops according to the law $I / I_{0}=1-n \cdot x /\left(x+x_{0}\right)$. 


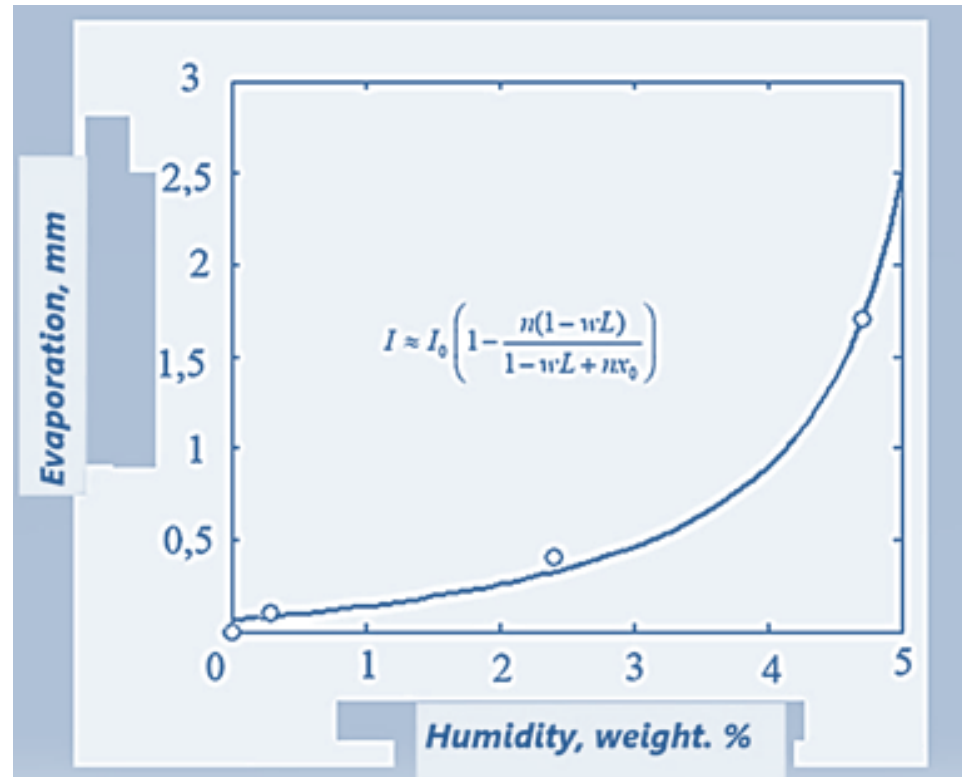

Figure 3: Dependence of evaporation on moisture for open sands. Approximation by function (2) with parameters $\mathrm{L}=100 \mathrm{~cm} ; \mathrm{n}=0.7 ; \mathrm{xO}=0.34 \mathrm{~cm}$.

Moisture evaporation in arid regions takes place during the warm period of the year, when the amount of heat during the day is enough for 2--3 $\mathrm{mm}$ of moisture to evaporate within a few hours and a dry layer of sand appears on the surface. Further evaporation is limited by the diffusion process and, having been reduced to tenths of millimeters per day, depends little on weather conditions. Using this feature, N.F. Kulik proposed empirical dependencies [4] for the numerical determination of seasonal physical evaporation, including evaporation from the soil and sediments spent on the wetting of living aboveground organic matter and bedding. The empirical formulas were based on data on one-time precipitation, the number of rainy and rainless days, and the average daily intensity of physical evaporation from a wet and dry surface. Thus, using the obtained dependences, it is possible to divide the total evaporation into its two components -- transpiration and physical evaporation. The formulas given in the work [4] can be used for all arid regions of Russia, but they require adjustments in terms of terms and place of their application. In the presented form they are suitable for the South of the Russian Federation. The calculation of the physical evaporation using the formulas obtained was made by the author using data for 22 years (1946--1967) of eighteen meteorological stations located on the sandy arrays or in close proximity to them. It is established that the greatest physical evaporation is observed in areas with the maximum amount of precipitation. With a decrease in summer precipitation, evaporation decreases. However, the proportion of precipitation spent on evaporation increases. Thus, for example, in the Pridonsky overgrown sands, $120--110 \mathrm{~mm}$ is spent 
on physical evaporation in summer, and 75--90 mm on Astrakhan sands, or 40--50 and $60--70 \%$ of the sum of summer precipitation respectively.

The data on evaporation given in the work [9] were thoroughly analyzed by us in order to identify the nature of the process of moisture evaporation in arid zones. Averaged over the years, the observations of precipitation were processed to identify a suitable theory. For this purpose, analytical expressions (formulas) were chosen empirically, by a nonlinear least squares method. As it is noted above, the theoretical studies of soil volatility are very limited. This is indicated by the authors whose scientific interest was the mechanical and strength properties of soils in construction, the problems of heat and water balance, evaporation from a water surface [1--4], and also purely theoretical [5, 16-17]. The conditions for evaporation are quite different. They can be divided into external -- climate (atmospheric temperature, wind, relative air humidity, solar radiation, etc.) and internal -- hydrophysical properties of soils (TMC, density, carbon content, porosity, etc.). In the open space during evaporation from a water surface, the evaporation rate is described by the formula

$$
I=I_{0}\left(1-e^{-\alpha t}\right),
$$

which is a differential model solution

$$
\frac{d I}{d t}=\alpha\left(I_{0}-I\right)
$$

where $I_{0}$ is the potential evaporation (the maximum possible), $\alpha$ is the coefficient characterizing the evaporation rate. The model (6) was obtained under the assumption that the climatic conditions are stationary, which determine the evaporation rate using the coefficient $\alpha$. The differential equation (6) is phenomenological expression of processes with feedback. The value $\left(I_{0}--l\right)$ reflects the deviation of the current evaporation I from the potential. In fact -- this is a lack of moisture. The higher the difference $\left(I_{0}--I\right)$-- the higher the evaporation rate. According to averaged long-term data [4], precipitation, as a rule, exceeds physical evaporation. The evaporation nonlinear dependence on precipitation is formally described by the model (6) with high accuracy, confirming the validity of the phenomenological interpretation with the introduction of feedback, without going into the physics of the phenomenon. In Figure 4 a linearized baseline curve on a semi-logarithmic scale shows.

From this, we can conclude that the differential model (6) is qualitatively adequate to reality. The numerical estimates of this adequacy are reflected just now in the coefficient of determination $R^{2}$ of the regression procedure in the least squares method.

The non-linearity of the processes of moisture movement in dispersed heterogeneous media, expressed by power dependence, was noted by many authors, both theoretically 
and experimentally. The semi-empirical model of the Van Gonuchten [23, 25--28] links the hydrophysical parameters of soils with their ability to retain and conduct moisture. Based on these semi-empirical assumptions, we interpreted the evaporation phenomenon from the surface of sand massifs from the energy point of view, which connects the soil moisture with the matrix potential (pressure) [2]. In Figure 5, the linearization of the power function $l=I_{0} \cdot w^{n}$ was performed on a double-logarithmic scale. After the logarithms of both parts of the equation, we obtain the linear dependence $I_{n} l=n$ $\cdot I_{n} w+I_{n} I_{0}$. The approximation by the power model from the point of view of accuracy (adequacy) is not much different from the previous one -- phenomenological in the form of an exponent (linearization in a semi-empirical scale).

The physical validity of the power interpretation is obvious. However, there is no concrete picture of evaporation in the form of a closed analytical expression. This is due to the difficulty of solving problems on mass transfer in inhomogeneous dispersed soils, which form the subsurface moisture complex phase structure. Averyanov S.F. [1] model is one of the few with a sufficient degree of detail and describes the state of soil moisture using capillaries in the form of a tubular structures dense package using the classical laws of Poiseuil and Darcy. This model led the author to power dependence between moisture conductivity and humidity in unsaturated soils.

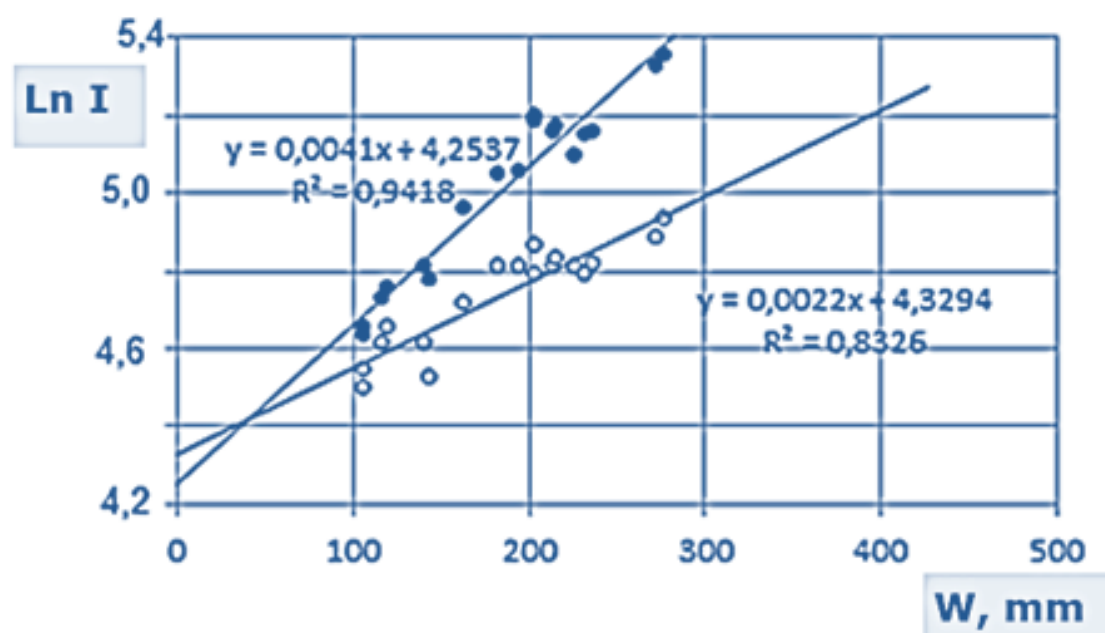

Figure 4: Dependence of moisture lost during the summer months due to physical evaporation on a semilogarithmic scale. The approximation in the form of a linear function $\ln l=a \cdot w+b: \ln l=0,0041 \cdot w+4.254$ for protective forest stands and $\ln l=0,0022 \cdot w+4.329$ for open sands. 


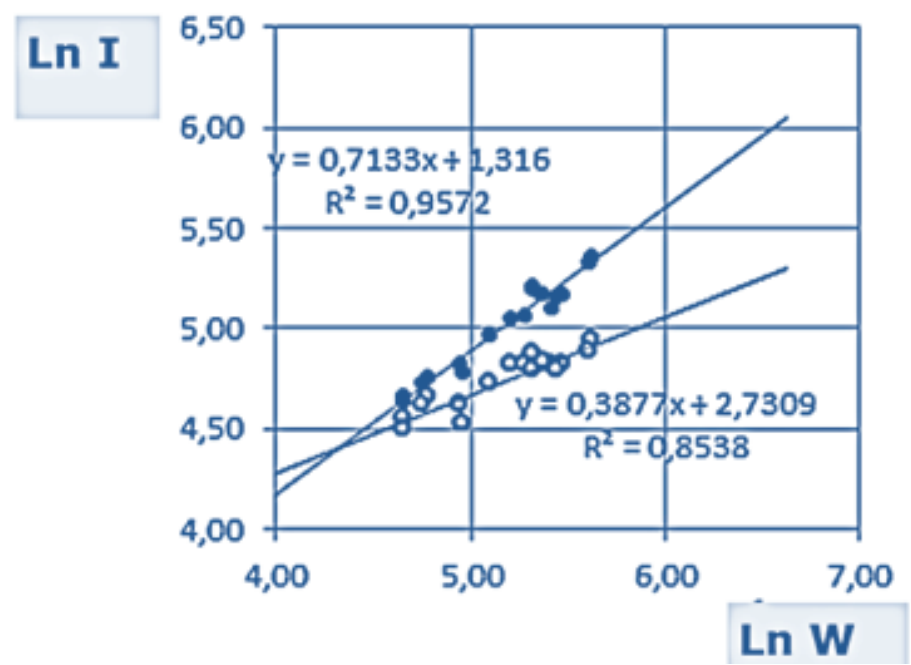

Figure 5: Dependence of moisture lost during the summer months due to physical evaporation on a double logarithmic scale. Approximation in the form of a linear function $\ln l=a \cdot \ln w+b: \mathrm{n} l=0.0041 \cdot \ln w+4.254$ for protective forest plantations and $\ln /=0.0022 \cdot \ln w+4.329$ for open sands.

\section{Conclusion}

The results obtained indicate that evaporation reflects the moisture removal process taking into account the soil water energy state. If the evaporation process in balance models is considered as averaged over long-term observations, then the dependence of the evaporation rate on humidity should be described by a power law, which allows making forecasts in dynamic water balance problems. The intensity of evaporation is determined by the state of the soil moisture: the higher the pressure the water is retained, the lower the evaporation. The greatest evaporation is observed in dispersed soils in the presence of free and capillary moisture in them. The smallest is when water is connected by capillary-sorption forces. In evaporation processes mathematical modeling, the relationship of evaporation with the moisture potential should be described by power dependence. At the same time, each value of pressure $P$ (humidity $w$ ) corresponds to a certain value of evaporation intensity regardless of the soil type, which allows using the obtained dependence to predict soil moisture loss due to evaporation. The methods of mathematical modeling for solving dynamic problems of the soil water regime during irrigation as a whole require development and improvement. The results given in this paper indicate in our opinion, this need. 


\section{Acknowledgement}

The authors would like to thank their colleagues for their contribution and support to the research. They are also thankful to all the reviewers who gave their valuable inputs to the manuscript and helped in completing the paper.

\section{Conflict of Interest}

The authors have no conflict of interest to declare.

\section{References}

[1] Budagovsky, A. I. (1981). Evaporation of soil waters. In collection: Physics of soil waters. Moscow: Science.

[2] Konstantinov, A.R. (1968). Evaporation in nature. Leningrad: Hydrometeoizdat.

[3] Korolev, V.A., Bludushkina, L.B. (2013). Interrelation of the moisture potential $n$ soils with the parameters of moisture evaporation from them. Journal of Engineering geology.

[4] Kulik, N.F. (1979). Water regime of arid zone sands. Leningrad: Gidrometeoizdat.

[5] Nerpin, S.V., Chudnovsky, A.F. (1967). Soil physics. Moscow: Science.

[6] Panina, S.S., Shein, E.V. (2014). Mathematical models of moisture transfer in the soil: the value of the experimental provision and the upper boundary conditions. Moscow University Bulletin, Series 17: Soil Science, no. 3.

[7] Shein, E.V. (2005). Soil physics course. Moscow: Publishing House of Moscow State University.

[8] Schaap, M.G., Leij, F.J., van Genuchten, M.Th. (2001). ROSETTA: a computer program for estimating soil hydraulic parameters with hierarchical pedotransfer functions. Journal of Hydrology.

[9] Korolev, V.A., Fedyaeva, E.A. (2012). Comparative analysis of thermal transfer in dispersed soils of different granulometric compound. Journal Engineering geology.

[10] Gardner, W.R., Hiller, D.I. (1962). The relation of external evaporative conditions to the drying of soils. Journal of Geophysical Research.

[11] Salugin, A.N. (2017). Restoration of the soil hydrophysical characteristics by using mathematical modeling. Ways to improve the efficiency of irrigated agriculture, collected works RosNIIPM. Novocherkassk. 
[12] Salugin, A.N. (2018). The use of the main hydrophysical characteristics for modeling the vertical movement of moisture in the aeration zone. Proc. of the Lower Volga Agro-University Comp.

[13] Salugin, A.N., Kulik, A.K., Vlasenko, M.V. (2018). Numerical modeling of the moisture vertical movement in the aeration zone. Proc. of the Lower Volga Agro-University Comp.

[14] Salugin, A.N., Kulik, A.K. (2017). Hydrophysical characteristics of sandy soils: modeling the restoration of water-holding capacity. Russian Agricultural Science.

[15] Grifoll, J., Gasto, J.M., Cohen, Y. (2005). Non-isothermal soil water transport and evaporation. Advances in Water Resources.

[16] Averyanov, S.F. (1949). The dependence of the soil permeability on the air content (Report Academy of Sciences of the USSR).

[17] Voronin, A.D. (1990). Energy concept of the soil physical condition. Soil Science.

[18] Salugin, A.N., Petrov, V.I. (2017). System dynamics in simulation modeling of irrigation water regime. Proc. of the Lower Volga Agro-University Comp.

[19] Salugin, A.N., Kulik, A.K., Vlasenko, M.V. (2018). Dynamics of water balance elements in the models of soil hydrological processes. Russian agricultural science.

[20] Salugin, A.N. (2018). Simulation modeling of irrigation regime. Irrigated agriculture.

[21] Salugin, A.N. (2015). Structural model of the region water balance. VolgGASU Bulletin. Volgograd.

[22] Salugin, A.N., Kulik A.K., Vlasenko M.V. (2017). Moisture permeability of unsaturated soils of the arid zone. Russian Agricultural Science.

[23] Simunek, J., van Genuchten, M.Th., Sejna, M. (2007). Development and Appllcatlons of the HYDRUS and STANMOD Software Packages and Related Codes. Vadose Zone Journal.

[24] Gael, A.G., Smirnova, L.F. (1999). Sands and sandy soils. Moscow: Geos.

[25] Gelfan, A.N. (2007). Dynamic-stochastic modeling of the snowmelt runoff formation. Moscow: Nauka.

[26] Van Genuchten, M.Th. (1980). A closed-form equation for predicting the hydraulic conductivity of unsaturated soils. Soll Scl. Soc. Am. Journal.

[27] Wosten, J.H. M., van Genuchten, M.Th. (1988). Using texture and other soll properties to predict the unsaturated soil hydraulic functions. Soll Se Soc. Am. Journal.

[28] Langergraber, G., Simunek, J. (2005). Modeling variably-saturated water flow and multi-component reactive transport in constructed wetlands. Vadose Zone Journal. 